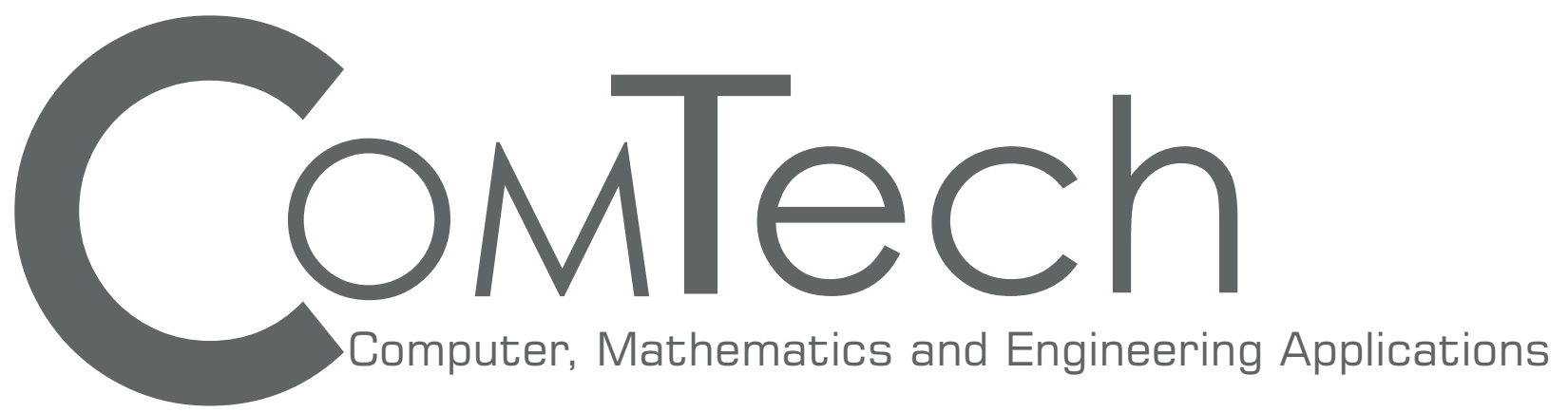

Vol. 4 No. 1 Juni 2013

Pelindung

Penanggung Jawab

Ketua Penyunting

Penyunting Pelaksana

Editor/Setter

Sekretariat

Alamat Redaksi

Terbit \& ISSN
Rektor BINUS University

Direktur Riset dan HKI, BINUS University

Ngarap Im Manik

Bens Pardamean

Iwa Sungkawa

Khristian Edi Nugroho

Sigit Wijaksono

Sherly Hartono

Ford Lumban Gaol

Sunarya Djajaprawira

Tri Pudjadi

Hudiarto

Anderes Gui

I Gusti Made Karmawan

Rinda Hedwig

Suparto Darudiato

Endang Ernawati

Angga Ferdiansyah

Sari Oktaviani

Nuriana Firda

I.Didimus Manulang

Holil

Direktorat Riset dan HKI

Universitas Bina Nusantara

Kampus Anggrek, Jl.Kebon Jeruk Raya 27

Kebon Jeruk, Jakarta Barat 11530

Telp. 021-5345830 (hunting), 5327630 ext.

6129/1189

Fax 021-5300244

Email:manik@binus.edu/holil@binus.edu

Terbit 2 (dua) kali dalam setahun

(Juni dan Desember)

ISSN: 2087-1244 


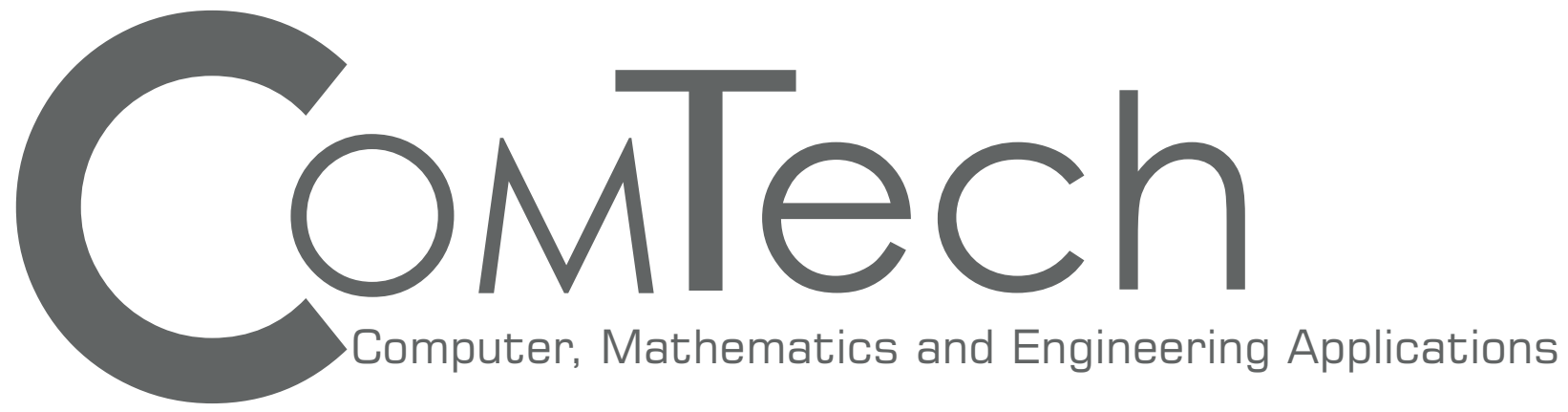

\section{Vol. 4 No. 1 Juni 2013}

\section{DAFTAR ISI}

\section{Albertus Prawata}

Penggunaan Fisikal Model dalam Perancangan Arsitektur

\section{Michael Tedja}

Analisa Rasio Parkir Mobil untuk Kantor Swasta di Jakarta

\section{Sigit Wijaksono}

Pengaruh Lama Tinggal terhadap Tingkat Partisipasi Masyarakat dalam

Pengelolaan Lingkungan Permukiman

Yosica Mariana

Tipologi Bangunan di Jalan Pakubowono Kebayoran Baru, Jakarta Selatan

Achmad Reza Viyanto; Okhran Steve Latuihamallo; Franky Mangihut Tua;

Anderes Gui; Suryanto

Manajemen Risiko Teknologi Informasi: Studi Kasus Pada Perusahaan Jasa ..

\section{Angelina Permatasari}

Perancangan Sistem Informasi Penjualan pada Apotek

Hari Setiabudi Husni; Firman Arifin; Yuliyanti

Logika Fuzzy untuk Audit Sistem Informasi

Haris Setia Budi; Wednes Pujiasmoro; Herjandi Wijaya; Yuliyanti

Analisis dan Perancangan Sistem E-Marketing pada PT Nordic Lift Truck

\section{Tangkas Udiono}

Evaluasi Kepuasan Mahasiswa terhadap Sistem Informasi Penjadwalan Kuliah

Biro Administrasi Umum dan Keuangan Universitas XYZ

I Gusti Made Karmawan

Implementasi RFID pada Perusahaan Penyewaan Mobil.

Yanti; Yunita Fransisca; Jacklyn Suwargo

Pengembangan Proses Bisnis dan Rancangan Aplikasi Sistem Informasi Penerimaan dan

Penilaian Peserta CO - ASS pada RSUD

Zahedi

Model Terintegrasi Penjadwalan Batch dan PM dengan Kriteria Minimalisasi

Biaya Simpan, Setup dan PM pada Mesin Dengan Increasing Failure Rate.

\section{Tanty Oktavia}

Perancangan Model Sistem Informasi Penunjang Operasional pada

Lembaga Bimbingan Belajar 


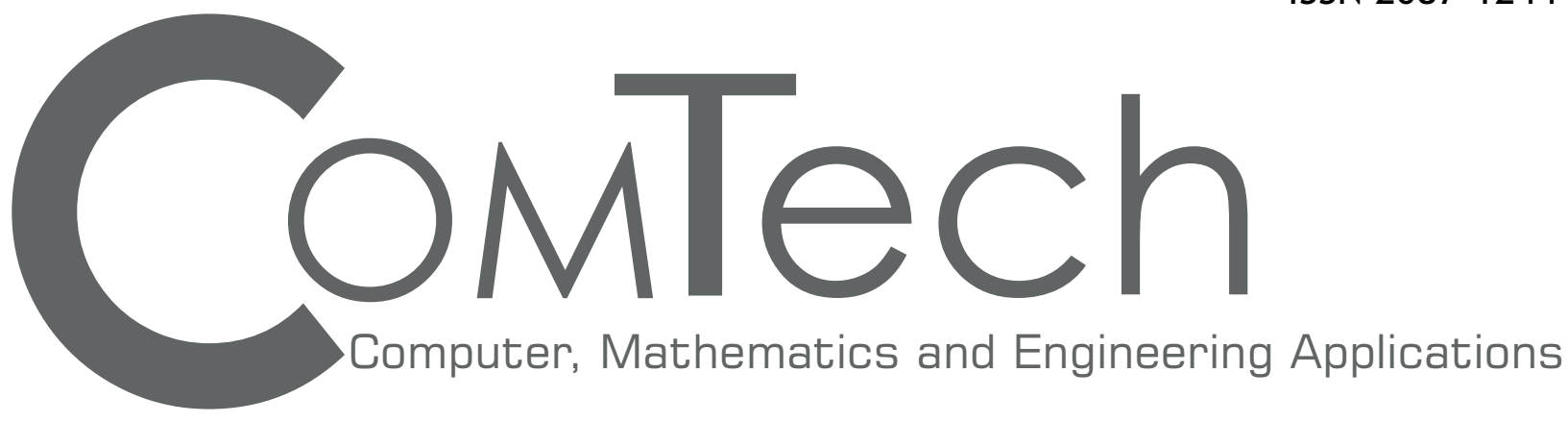

\section{Vol. 4 No. 1 Juni 2013}

\section{DAFTAR ISI}

Desi Maya Kristin; Wahyu Sardjono

Evaluasi Knowledge Management System di Kompas Gramedia Menggunakan Analisis Faktor

Devyano Luhukay; Yohannes Kurniawan; Titan

Analisis dan Perancangan Sistem Informasi Penjualan dan Persediaan pada PT XYZ

\section{Wahyu Sardjono}

Model System Dynamics Infrastruktur BTS Ramah Lingkungan Daerah Rural untuk

Optimalisasi Perhitungan ARPU

Agus Hamdi

Analisis Sistem Informasi Pelayanan Jasa In-House Training pada

PT Sigma Global Internasional Jakarta

Albert V. Dian Sano

Simulasi Penghitungan Online Kredit Pemilikan Rumah Bank XYZ

berbasis Web di Portal Finansial

Arief Dwi Hartadi; Oktalia Juwita

Perancangan Data Warehouse dan Penerapan Teknik Clustering Spatial pada

Wesel: Studi Kasus PT XXX

Dewan Pelawi

Pembuatan Sistem Informasi dengan Analisis dan Perancangan Berorientasi Objek

Edwin Yoyada Pratama

Reliable IT Service Comes with Price

Eka Miranda

Perancangan Model Data Warehouse dan Perangkat Analitik untuk Memaksimalkan

Proses Pemasaran Hotel: Studi Kasus pada Hotel ABC

Eka Miranda; Julisar

Perancangan Model Hirarki Keputusan dan Sistem Basis Data pada Sistem Informasi

Sumber Daya Manusia Sub-Sistem Rekrutmen dengan Metode Berjenjang

Eli Suryani; Muhammad Fadli

Pengukuran Kinerja Efektif Departemen Pengembangan Sistem Informasi dengan Metode Balanced Scorecard pada PT XYZ

\section{Harijanto Pangestu}

Model Perancangan Sistem Pemesanan Tiket Bus Antar Kota Antar Propinsi Khusus di Cabang

\section{Hudiarto}

Pilihan Metode Manajemen Proyek dan Pengembangan Aplikasi pada

Perusahaan Pemula Pengembang Perangkat Lunak di Jakarta. ... 


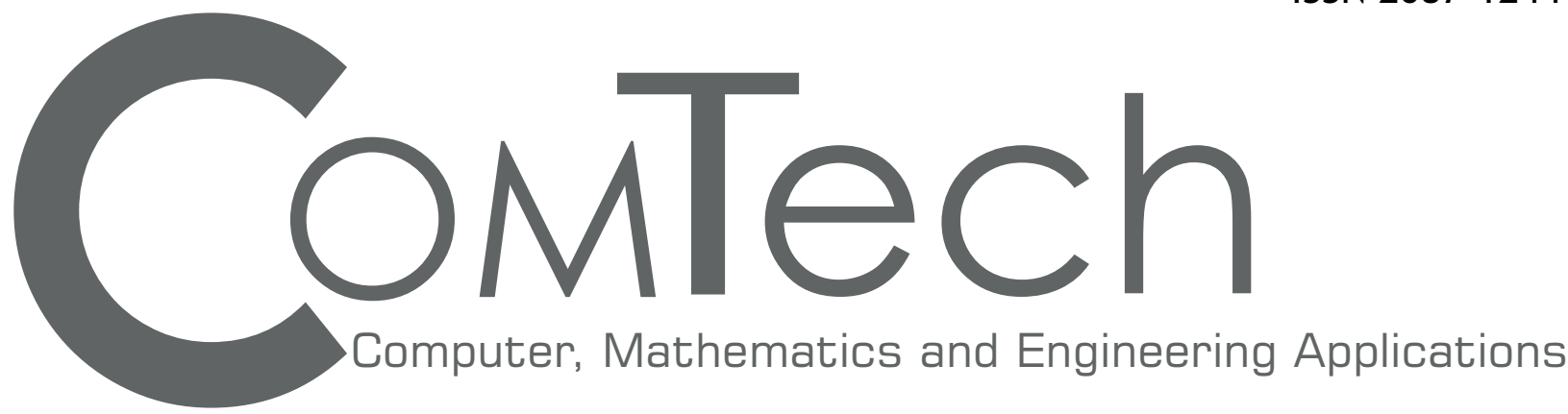

\section{Vol. 4 No. 1 Juni 2013}

\section{DAFTAR ISI}

\section{Ikrar Adinata Arin}

Perancangan Sistem Informasi Signature Verification System for Banking

Indrajani

Model Object Relational Database pada Aplikasi Notifikasi SMS

\section{Lianna Sugandi}

Dampak Implementasi Change Management pada Organisasi

\section{Marisa Karsen}

Information Technology (IT) Improvement at PT Sumber Alfaria Trijaya

\section{Mediana Aryuni}

Penerapan Ensemble Feature Selection dan Klasterisasi Fitur pada

Klasifikasi Dokumen Teks

\section{Rahayu Ary Yuniarti}

Perancangan Man Hour Integrated Control Application pada

Perusahaan Berbasis Project

\section{Tanty Oktavia}

Model Konseptual Sistem Informasi sebagai Penunjang Operasional

Perusahaan Dagang

Tri Pujadi; Harisno

Pengembangan Model Perangkat Ajar Berbasis Animasi:Studi Kasus Mata Ajar Biologi pada

SMP Yaspia dan SMK Bina Manajemen Cakung Jakarta Timur

Gemma Eka Santoso; Gita Ayu; Nike Septivani

Lean Strategy Implementation to Improve Throughput in Assembly Line:

DUL-DB21SSC Manufacturing Process at PT X

Ferdian Hartoyo; Yudha Yudhistira; Andry Chandra; Ho Hwi Chie

Penerapan Metode DMAIC dalam Peningkatan Acceptance Rate untuk

Ukuran Panjang Produk Bushing

Jevi Rosta; Hendy Tannady

Aplikasi AHP dalam Menentukan Kandidat Gubernur DKI Jakarta 2012-2017

Rida Zuraida

Preferensi Konsumen Pada Aktivitas Callback dan Telemarketing di Restoran Cepat Saji .......

Karto Iskandar; Jefriyanto; Halena Giovanni; Candra Gunawan

Penerapan Sistem Personalisasi Akun pada Admisi Online Binus University 


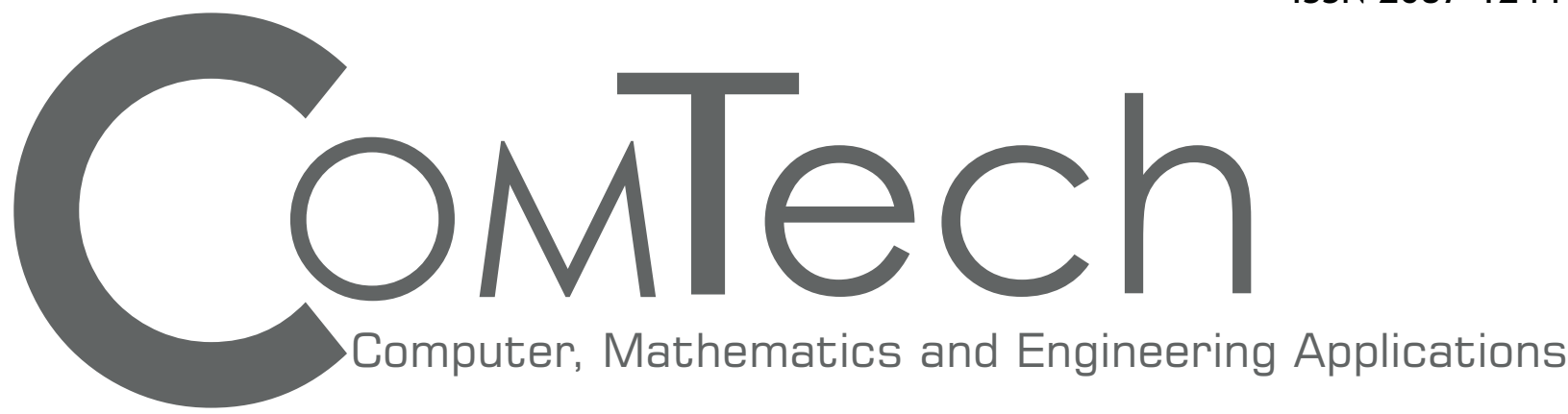

\section{Vol. 4 No. 1 Juni 2013}

\section{DAFTAR ISI}

Andiyono; Rokhana Dwi Bekti; Edy Irwansyah Analisis Faktor yang Mempengaruhi Angka Buta Huruf Melalui Geographically

Weighted Regression: Studi Kasus Propinsi Jawa Timur

Choirul Huda; Andika Gilang Nugraha; Alwin Ghifari; Axel Didha Dewangga

Analisis dan Perancangan Aplikasi Basis Data Penilaian Kinerja Karyawan Menggunakan Metode 360-Degree Feedback berbasis Web pada PT IFS Solutions Indonesia

Djunaidy Santoso; Haryono Soeparno; Ayuliana

Keuntungan Algoritma Bezier, B-Spline di Dunia Industri

Alex Chandra; Tonny Lion Kencana; Yurri Kurnianingsi; Elidjen

Pengembangan Aplikasi Media Komunikasi Badan Pengawas Pemilu

Republik Indonesia Berbasiskan Web dan Wap

\section{Gredion Prajena}

Analisis dan Perancangan Data Warehouse untuk Penjualan, Identifikasi Status Distributor, dan Perpanjangan Masa Aktif Distributor pada PT Harmoni Dinamik Indonesia

Reina; Irma Irawati Ibrahim; Josef Bernadi Gautama

Perancangan Sistem Informasi Mentoring untuk Perguruan Tinggi

\section{Reina}

Peningkatan Efisiensi dan Efektifitas Layanan Dosen dalam Pemanfaatan Web Application ....

Irpan Hidayat

Tingkat Kepuasan Parkir Kampus Anggrek Binus University Ditinjau dari Fasilitas

Geometri dan Survei Kepuasan Parkir

Irpan Hidayat

Analisis Perhitungan Jembatan Gelagar I pada Jembatan Jalan Raya dan

Jembatan Kereta Api

A Haris Rangkuti

Deteksi 4 Tanda Vital Pasien Rumah Sakit berbasis Fuzzy Database

Jonny

Analisis Incremental Kelayakan Penambahan Lini Perakitan Engine Motor PT ABC 